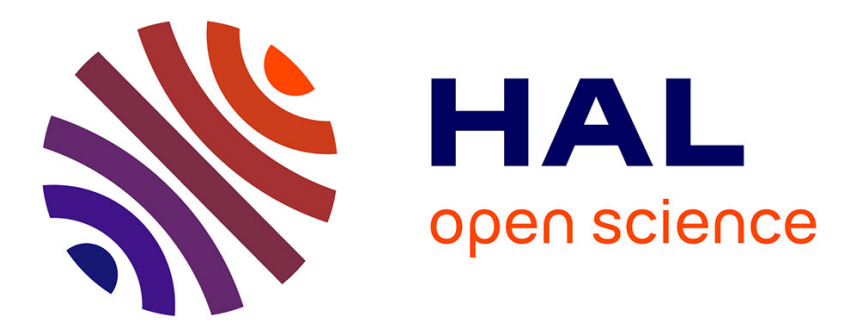

\title{
The currently declining incidence of cancer of unknown primary
}

Elie Rassy, Nicholas Pavlidis

\section{To cite this version:}

Elie Rassy, Nicholas Pavlidis. The currently declining incidence of cancer of unknown primary. Cancer Epidemiology, 2019, 61, pp.139 - 141. 10.1016/j.canep.2019.06.006 . hal-03485854

\section{HAL Id: hal-03485854 https://hal.science/hal-03485854}

Submitted on 20 Dec 2021

HAL is a multi-disciplinary open access archive for the deposit and dissemination of scientific research documents, whether they are published or not. The documents may come from teaching and research institutions in France or abroad, or from public or private research centers.
L'archive ouverte pluridisciplinaire HAL, est destinée au dépôt et à la diffusion de documents scientifiques de niveau recherche, publiés ou non, émanant des établissements d'enseignement et de recherche français ou étrangers, des laboratoires publics ou privés.

\section{(c) (1) $(5$}

Distributed under a Creative Commons Attribution - NonCommercial| 4.0 International 
Version of Record: https://www.sciencedirect.com/science/article/pii/S1877782119300566

Manuscript_1ad563eeb360e5234e2ecb3b6efb3983

The currently declining incidence of cancer of unknown primary

Elie Rassy MD, $\mathrm{MSc}^{1,2}$, Nicholas Pavlidis MD, $\mathrm{PhD}^{3}$

${ }^{1}$ Department of Medical Oncology, Institut Gustave Roussy, Villejuif, France.

${ }^{2}$ Department of Hematology-Oncology, Hotel Dieu de France University Hospital, Faculty of Medicine, Saint Joseph University, Beirut, Lebanon.

${ }^{3}$ University of loannina, Ioannina, Greece

Corresponding author: Elie Rassy MD, MSc. Department of Medical Oncology, Institut Gustave Roussy, Villejuif, France. Email: elie.rassy@hotmail.com 


\title{
The currently declining incidence of cancer of unknown primary
}

\begin{abstract}
Cancer of unknown primary (CUP) is a heterogeneous group of metastatic cancers for which a primary tumor cannot be identified after a standardized work-up. The biology of CUP has not been fully elucidated and epidemiologic data may be helpful in this regard. The variations in the incidencerate of CUP over time and between countries reflect changes in the risk factors for CUP, incidence trends of the primary tumors that potentially contribute to the burden of CUP and changes in the diagnostic technologies and practice. CUP accounted for 3-5\% of cancers in the historical series but its incidence seems to decline in the recent publications. This paper reviews the published cancerregistry studies in order to identify and understand the variations in the incidence-rates of CUP.
\end{abstract}

Keywords: cancer of unknown primary; CUP; epidemiology; incidence

\section{Introduction}

Cancer of unknown primary (CUP) represents a heterogeneous group of metastatic tumors for which a standardized diagnostic work-up does not identify the primary tumor at the time of diagnosis [1]. It is a well recognized clinical syndrome that is characterized by a widespread metastatic cancer with aggressive biological and clinical behavior [2]. The minority of CUP patients (20\%) has a favorable CUP subset characterized by a good prognosis whereas the majority $(80 \%)$ has an unfavorable CUP subset characterized by a poor outcome [3]. Chromosomal instability may account in part for these characteristics but the identification of the exact pathogenesis of CUP would yield a better understanding of its aggressiveness [4]. The epidemiology of CUP may be a gateway that provides insight into its biology. The comparison of population-based studies may identify patterns of incidence-rates among different populations which reflects changes in risk factors for CUP, incidence trends of the primary tumors that potentially contribute to the burden of CUP and changes in the diagnostic technologies and practice [5]. For this purpose, we reviewed the published studies of the published cancer-registry data in order to identify and understand the variations in the incidencerates of CUP.

\section{CUP trends in population-based studies}

An overview of the CUP incidence-rates shows that the epidemiology of CUP in Europe has witnessed an initial increase until 1990 or 2000 , depending on the countries, before starting to decrease (Figure 1). The peaks of incidence-rates occurred around 1980 in the United States and have been decreasing by $3.6 \%$ per year in the last decades [6]. The Unites States experienced decreases earlier than other countries around 1980 whereas the European countries started their decreasing trend around 1990 in Norway [7] and around 2000 in Scotland [5], Switzerland [8], Netherlands [9,10] and Sweden [1113]. Australia also had a similar trend to the European countries [14]. 


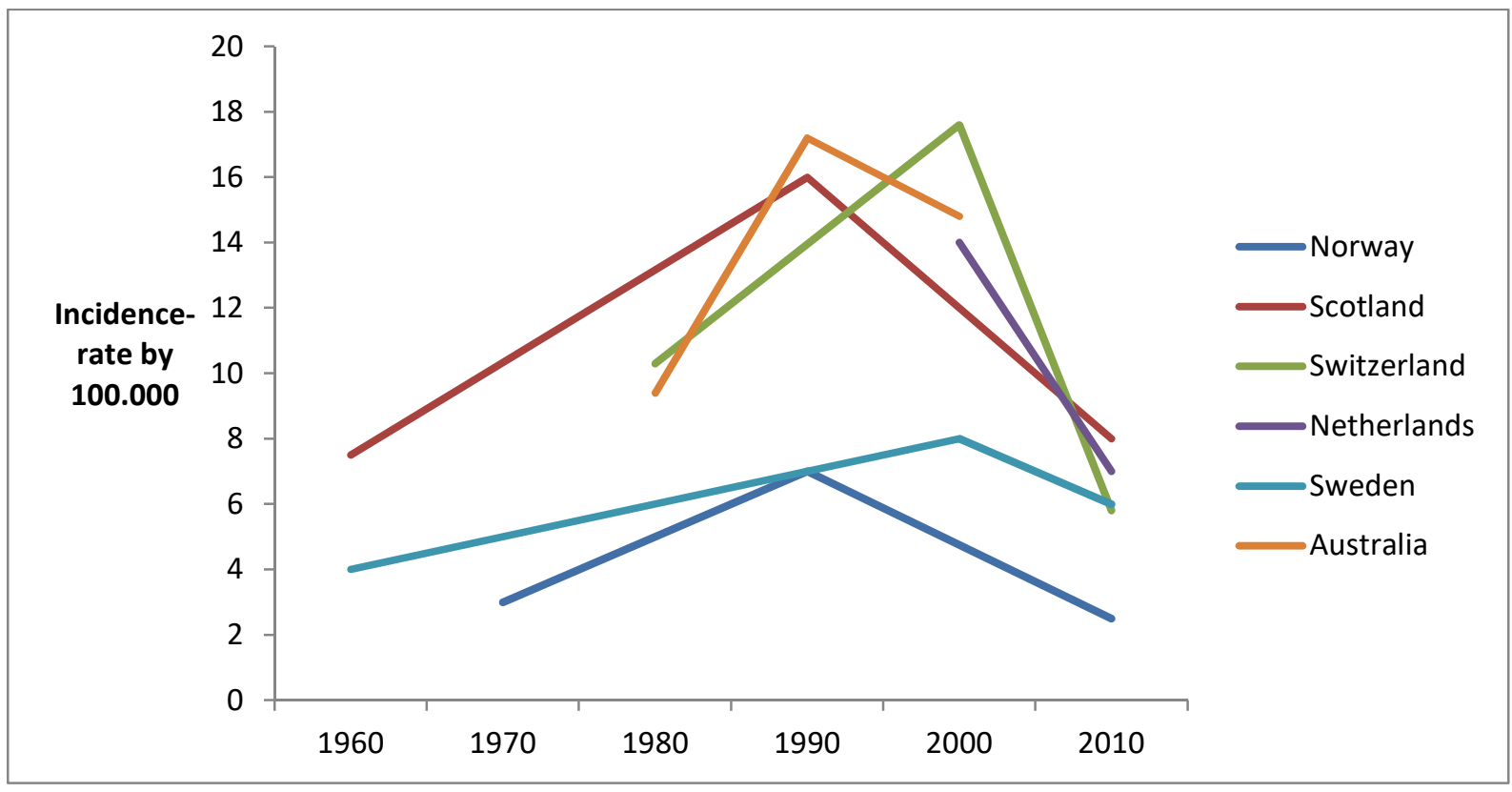

Figure 1: Schema of the approximate variations in the incidence-rates of cancer of unknown primary by country

In Norway, the incidence-rate increased between 1970 and 1990 from 2-4 to 6-8 per 100.000 and decreased thereafter to 2-3 per 100.000 in 2010 [7]. The percentage of CUP patients increased from $2-3 \%$ in 1970 to $4-5 \%$ in 1990 and deceased thereafter to $1.7 \%$ [7].

In Scotland, the incidence-rates of CUP increase from 7-8 per 100.000 in 1960s to a peak of 14-18 per 100.000 in the early to mid-1990 followed by a steeper decrease to 8 per 100.000 in 2009 [5]. CUP represents $3.9 \%$ of cancer diagnosis during the period 1961-2010 and slightly decreased to $3.2 \%$ when limiting the period to 2001-2010 [5].

In Switzerland, the incidence-rate increased between 1981 and 1997 from 10.3 to 17.6 per 100.000 and decreased thereafter to 5.8 per 100.000 in 2014 . CUP accounted for $1.5 \%$ of cancer diagnoses in 1980 s, peaked to $2.1 \%$ in 1997 and decreased to $0.9 \%$ in 2014 [8].

In Netherlands, the published analysis does not report on the epidemiology of CUP before the year 2000 however the incidence-rate seemed to decrease from 14 to 7 per 100.000 between 2000 and 2012 [9]. The prevalence of CUP accounts for $2.5 \%$ in Netherlands during the time period 2000-2012 whereas it represented $4.0 \%$ in Southeast Netherlands during the time period 1984-1992 [9,10].

In Sweden, three population-based analyses have reported on the CUP epidemiology using the same registry [11-13]. Two of these studies included patients from the same time period 1960-2008 and showed different incidence-rates as they standardized their findings according to different populations [11,13]. Randen et al. reported an increased incidence-rate between 1960 and 2000 from 10 to 16 per 100.000 and thereafter decreased to 12 per 100.000 by 2007 [13]. Shu et al. on the other hand showed almost similar kinetics with an increased incidence-rate from 4 per 100.000 during the early 1960 s to 8 per 100.000 in the late 1990 s and declined thereafter to 6-7 per 100.000 in 2005 [11]. Bevier et al. reported on the study period 1987-2008 and an initially increasing incidence-rate from 7 to 8 per 100.000 between the time period of 1987-1994 and 1995-1999 before a decrease thereafter to 6 per 100.000 in 2008 [12]. CUP accounts for around 3\% of all diagnosed cancer [13]. 
In South Australia, the incidence-rates of CUP increased from 9.4 per 100.000 in 1977-1980 to 15.1 per 100.000 in 1981-1984 and tended to peak at 17.2 per 100.000 in 1993-1996 before declining to 14.8 per 100.000 in 2001-2004 [14]. The prevalence of CUP accounts for $3.5 \%$ of cancer diagnosis [14].

\section{Understanding the variation in the CUP trends}

The estimates of the incidence of CUP depend crucially on its definition. CUP is widely defined as a metastatic tumor for which a standardized diagnostic work-up fails to identify the site of origin at the time of diagnosis [1]. Unfortunately this definition under-estimates the population burden of disease as it excludes cancers that are not microscopically verified which corresponds to $20-60 \%$ of patients with CUP $[5,6]$. Effectively, the percentage of CUP decreases from $3.2 \%$ to $0.3 \%$ when mandating microscopic confirmation in the same time population and time period [5]. The variation in the definition of CUP between different epidemiological studies highlights the lack of an international agreement on guidelines for the registration of CUP as well as a standard grouping of diagnostic codes for analysis [15]. Cancer registries of CUP may not truthfully reflect the true incidence of CUP as they are also affected by the inadequate and low utilization of diagnostic services as well as poor documentation and notification of diagnostic results. Moreover, the CUP incidences are affected by inadequate cancer registry practices [16]. An audit of the New South Wales Central Cancer Registry reclassified $30.0 \%$ of the CUP cases into known primary tumors thus decreased the incidence rates of CUP [17]. This issue may be speculated in the Swedish database especially that $2 \%$ of the patients with CUP were diagnosed with a new cancer within 5 years which may be suggestive of a potential primary culprit [13].

The differences in the CUP incidence-rates across the different age groups show that the main variations occur among older patients $[5,13]$. CUP of the elderly has risen as a particular entity [18]. Among individuals older than 60 years of age, the incidence-rate for CUP in the digestive tract has increased markedly [12]. The most common location of metastasis in this age group is the liver which may be explained by the similar age-specific incidence for colorectal cancer [12]. Similarly, the agespecific incidence trend for bone CUP can be explained by a similar age-specific incidence for prostate cancer with bone as most common metastatic site [12]. It is noteworthy that the searching for the primary site seems less intensive in older patients $[5,13]$.

The variations in the CUP incidence-rates allude to the possible pathogenesis of CUP. The overall increases are explained by the increasing trends of any cancer every year and the increased awareness of CUP as a diagnostic entity [5]. On the other hand, the decreases are explained by several reasons. First, the incidence of CUP may be decreasing in parallel to the incidence of lung cancer which is amongst the most commonly reported primaries in CUP [12-14]. Second, the better understanding of the risk factors for CUP account in part for the variations in the CUP epidemiology. The incidence-rates of CUP are replicated in different birth cohorts which suggests modest birth cohort effects [11]. Moreover, the understanding of familial clustering leads to targeted investigations for primary sites which allow a higher rate of primary tumor identification [19]. The sociodemographic factors account for a part of the variations in the CUP incidence-rates. The modifications in the risk factors of CUP, such as the steady decline in smoking, explains in part the decreased prevalence of CUP [20]. Last, the wider access to the improved diagnostic methods such as modern imaging and gene profiling technology allows an identification of primary sites thus lowers the incidence-rates of CUP [5]. For example, CT scan better identifies lung cancers which are the most common primaries for brain CUP and PET scans that contributes to the management of cervical adenopathies from CUP and those with single CUP metastasis [1,21]. Moreover, gene expression 
profiling predicts the site of origin in $>95 \%$ of patients compared to $35-55 \%$ with immunohistochemical staining thus lowering the incidence-rates of CUP [22].

\section{Conclusion}

This analysis of population-based registries presented above show that the incidence-rate of CUP has been decreasing over time. The reasons for this decline may be due to the decreased occurrence of potential primaries for CUP or the improvement in the diagnostic methods such as advanced imaging and molecular profiling. Unfortunately, the analysis of cancer registries are limited in the clinical dimension as they lack specific details on the diagnostic work-up to identify the primary tumor. Solid conclusions concerning the reasons for this decline in the incidence-rate of CUP cannot be withdrawn from the current literature and any attempt in this regard is speculative. Epidemiologic research in this regard is strongly encouraged to understand the reasons behind these variations as may shed some light on the enigmatic biology of CUP.

\section{Declarations of interest: None}

Acknowledgment: None

\section{References}

[1] K. Fizazi, F.A. Greco, N. Pavlidis, G. Daugaard, K. Oien, G. Pentheroudakis, ESMO Guidelines Committee, Cancers of unknown primary site: ESMO Clinical Practice Guidelines for diagnosis, treatment and follow-up, Ann. Oncol. Off. J. Eur. Soc. Med. Oncol. 26 Suppl 5 (2015) v133-138. doi:10.1093/annonc/mdv305.

[2] N. Pavlidis, G. Pentheroudakis, Cancer of unknown primary site, Lancet Lond. Engl. 379 (2012) 1428-1435. doi:10.1016/S0140-6736(11)61178-1.

[3] N. Pavlidis, E. Briasoulis, J. Hainsworth, F.A. Greco, Diagnostic and therapeutic management of cancer of an unknown primary, Eur. J. Cancer Oxf. Engl. 1990. 39 (2003) 1990-2005.

[4] J. Vikeså, A.K.H. Møller, B. Kaczkowski, R. Borup, O. Winther, R. Henao, A. Krogh, K. Perell, F. Jensen, G. Daugaard, F.C. Nielsen, Cancers of unknown primary origin (CUP) are characterized by chromosomal instability (CIN) compared to metastasis of know origin, BMC Cancer. 15 (2015) 151. doi:10.1186/s12885-015-1128-x.

[5] D.H. Brewster, J. Lang, L.A. Bhatti, C.S. Thomson, K.A. Oien, Descriptive epidemiology of cancer of unknown primary site in Scotland, 1961-2010, Cancer Epidemiol. 38 (2014) 227-234. doi:10.1016/j.canep.2014.03.010.

[6] E. Mnatsakanyan, W.-C. Tung, B. Caine, J. Smith-Gagen, Cancer of unknown primary: time trends in incidence, United States, Cancer Causes Control CCC. 25 (2014) 747-757. doi:10.1007/s10552-014-0378-2.

[7] O.T. Brustugun, A. Helland, Rapid reduction in the incidence of cancer of unknown primary. A population-based study, Acta Oncol. 53 (2014) 134-137. doi:10.3109/0284186X.2013.783230.

[8] C. Binder, K.L. Matthes, D. Korol, S. Rohrmann, H. Moch, Cancer of unknown primaryEpidemiological trends and relevance of comprehensive genomic profiling, Cancer Med. 7 (2018) 4814-4824. doi:10.1002/cam4.1689.

[9] C. Schroten-Loef, R.H.A. Verhoeven, I.H.J.T. de Hingh, A.J. van de Wouw, H.W.M. van Laarhoven, V.E.P.P. Lemmens, Unknown primary carcinoma in the Netherlands: decrease in incidence and survival times remain poor between 2000 and 2012, Eur. J. Cancer Oxf. Engl. 1990. 101 (2018) 77-86. doi:10.1016/j.ejca.2018.06.032.

[10] A.J. van de Wouw, M.L.G. Janssen-Heijnen, J.W.W. Coebergh, H.F.P. Hillen, Epidemiology of unknown primary tumours; incidence and population-based survival of 1285 patients in Southeast Netherlands, 1984-1992, Eur. J. Cancer Oxf. Engl. 1990. 38 (2002) 409-413. 
[11] X. Shu, K. Sundquist, J. Sundquist, K. Hemminki, Time trends in incidence, causes of death, and survival of cancer of unknown primary in Sweden, Eur. J. Cancer Prev. Off. J. Eur. Cancer Prev. Organ. ECP. 21 (2012) 281-288. doi:10.1097/CEJ.0b013e32834c9ceb.

[12] M. Bevier, J. Sundquist, K. Hemminki, Incidence of cancer of unknown primary in Sweden: analysis by location of metastasis, Eur. J. Cancer Prev. Off. J. Eur. Cancer Prev. Organ. ECP. 21 (2012) 596-601. doi:10.1097/CEJ.0b013e3283523468.

[13] M. Randén, L.-E. Rutqvist, H. Johansson, Cancer patients without a known primary: incidence and survival trends in Sweden 1960-2007, Acta Oncol. Stockh. Swed. 48 (2009) 915-920. doi:10.1080/02841860902862503.

[14] C. Luke, B. Koczwara, C. Karapetis, K. Pittman, T. Price, D. Kotasek, K. Beckmann, M.P. Brown, D. Roder, Exploring the epidemiological characteristics of cancers of unknown primary site in an Australian population: implications for research and clinical care, Aust. N. Z. J. Public Health. 32 (2008) 383-389. doi:10.1111/j.1753-6405.2008.00260.x.

[15] E. Schwartz, V.Y. Kofie, S.R. Sturgeon, Racial differences in ill defined cancer mortality in the United States and in the District of Columbia, J. Epidemiol. Community Health. 46 (1992) 390393.

[16] International Agency for Research on Cancer. Manual for cancer registry personnel. Lyon: International Agency for Research on Cancer, 1995, (n.d.).

[17] C.M. Vajdic, C.C. Er, A. Schaffer, T. Dobbins, L. Wyld, N.S. Meagher, J. Barrett, R.L. Ward, S.-A. Pearson, An audit of cancer of unknown primary notifications: A cautionary tale for population health research using cancer registry data, Cancer Epidemiol. 38 (2014) 460-464. doi:10.1016/j.canep.2014.05.004.

[18] K. Hemminki, N. Pavlidis, K.K. Tsilidis, K. Sundquist, J. Ji, Age-Dependent Metastatic Spread and Survival: Cancer of Unknown Primary as a Model, Sci. Rep. 6 (2016). doi:10.1038/srep23725.

[19] K. Hemminki, J. Ji, J. Sundquist, X. Shu, Familial risks in cancer of unknown primary: tracking the primary sites, J. Clin. Oncol. Off. J. Am. Soc. Clin. Oncol. 29 (2011) 435-440. doi:10.1200/JCO.2010.31.5614.

[20] R. Kaaks, D. Sookthai, K. Hemminki, A. Krämer, H. Boeing, E. Wirfält, E. Weiderpass, K. Overvad, A. Tjønneland, A. Olsen, P.H. Peeters, H.B. Bueno-de-Mesquita, S. Panico, V. Pala, P. Vineis, J.R. Quirós, E. Ardanaz, M.-J. Sánchez, M.-D. Chirlaque, N. Larrañaga, P. Brennan, D. Trichopoulos, A. Trichopoulou, P. Lagiou, G. Hallmans, K.-T. Khaw, T.J. Key, E. Riboli, F. Canzian, Risk factors for cancers of unknown primary site: Results from the prospective EPIC cohort, Int. J. Cancer. 135 (2014) 2475-2481. doi:10.1002/ijc.28874.

[21] K. Hemminki, H. Liu, A. Hemminki, J. Sundquist, Power and limits of modern cancer diagnostics: cancer of unknown primary, Ann. Oncol. Off. J. Eur. Soc. Med. Oncol. 23 (2012) 760-764. doi:10.1093/annonc/mdr369.

[22] J.D. Hainsworth, F.A. Greco, Gene expression profiling in patients with carcinoma of unknown primary site: from translational research to standard of care, Virchows Arch. Int. J. Pathol. 464 (2014) 393-402. doi:10.1007/s00428-014-1545-2. 